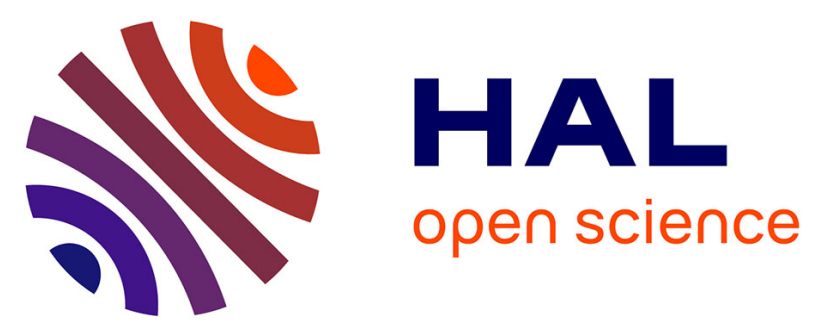

\title{
A Multidimensional Data Acquisition as a Preliminary Step to the Secondary Prevention of the Loss of Autonomy for Patients with Traumatic Injury and Stroke: An AMISIA Pilot Study
}

Stéphane Mandigout, Anaick Perrochon, Laure Fernandez, Nasser Rezzoug, Benoît Encelle, Ioannis Kanellos, Damien Ricard, Marinette Bouet, Michel Schneider, Stéphane Buffat

\section{- To cite this version:}

Stéphane Mandigout, Anaick Perrochon, Laure Fernandez, Nasser Rezzoug, Benoît Encelle, et al.. A Multidimensional Data Acquisition as a Preliminary Step to the Secondary Prevention of the Loss of Autonomy for Patients with Traumatic Injury and Stroke: An AMISIA Pilot Study. Innovation and Research in BioMedical engineering, 2020, 41 (6), pp.316-320. 10.1016/j.irbm.2020.06.010 . hal03107721

\section{HAL Id: hal-03107721 \\ https://hal.science/hal-03107721}

Submitted on 16 Apr 2021

HAL is a multi-disciplinary open access archive for the deposit and dissemination of scientific research documents, whether they are published or not. The documents may come from teaching and research institutions in France or abroad, or from public or private research centers.
L'archive ouverte pluridisciplinaire HAL, est destinée au dépôt et à la diffusion de documents scientifiques de niveau recherche, publiés ou non, émanant des établissements d'enseignement et de recherche français ou étrangers, des laboratoires publics ou privés. 
JETSAN 2019

\title{
A Multidimensional Data Acquisition as a Preliminary Step to the Secondary Prevention of the Loss of Autonomy for Patients with Traumatic Injury and Stroke: An AMISIA Pilot Study
}

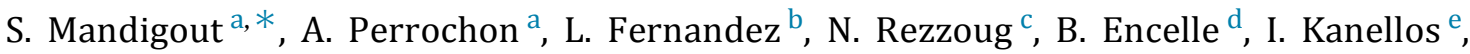 \\ D. Ricard ${ }^{f}$, M. Bouet ${ }^{g}$, M. Shneider ${ }^{g}$, S. Buffat ${ }^{f}$
}

${ }^{a}$ Université de Limoges, Laboratoire HAVAE EA 6310, F-87060, France

${ }^{\mathrm{b}}$ Université de Marseille, Institut des Sciences du Mouvement Humain UMR 7287, France

${ }^{\mathrm{c}}$ Université de Toulon, UFR STAPS, France

${ }^{\mathrm{d}}$ Université de Lyon CNRS, Université Lyon 1, LIRIS, UMR5205, F-69622, France

e Laboratoire LabSTICC - IHSEV/HAAL UMR 6285, France

${ }^{\mathrm{f}}$ Université Paris-Descartes, Laboratoire Cognition and Action Group UMR-MD4 8257, France

${ }^{\mathrm{g}}$ Université de Clermont-Ferrand - Auvergne, LIMOS UMR 6158, France

\section{h i g h l i g h t s}

- Cognitive disorders could be partly explained by the lack of activity.

Identifying the symptoms of activity re-

striction will define the intervention strategy.

Set of sensors will be combined to produce interpretable data for follow-up.

Artificial intelligence can be a way to

monitor and encourage each person's profile. g r a p hicala b s t r a t

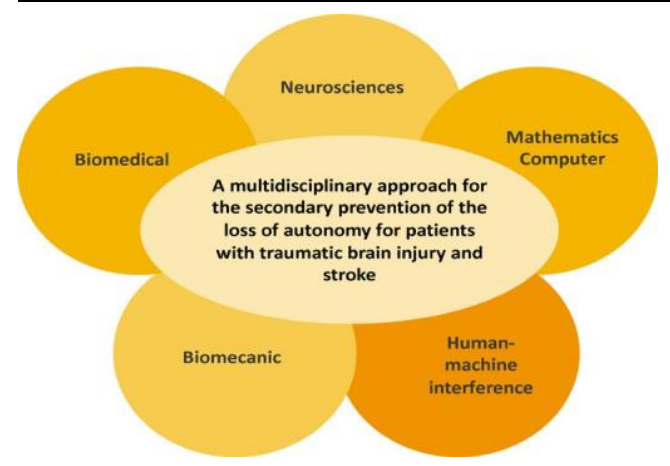

a b s t r a c t

Background: The aim of our study was to conduct an ad hoc data collection in healthy adults with the intention of extracting individual profiles to study the ability to effectively monitor one's health by extracting relevant indicators. As "each patient is a unique case", AMISIA (Defi CNRS AUTON project) proposes an integrated approach, combining medical health devices, information technology, and human factors to provide patients, health care actors and family caregivers with both the best incentives and a high degree of monitoring.

Method: We conducted a data collection experiment in Limoges with 61 participants at the Limoges University. Data were biographic elements, socio-economic profiles, cognitive performance (Corsi test results), a psychological battery (anxiety, fatigue, sleep), posture and gait measurement with 4 Imus and a Wii-balance board, and finally physical activity during a week at home (Armband sensors).

Results: For the Corsi virtual walking test, the median memory span for Group A was significantly less $(\mathrm{p}<0.001)$ than for Group B. Step count and active energy expenditure were significantly higher in Group B $(p<0.05)$. A multiple regression analysis showed that gender, active energy expenditure, fatigue and tendency to play video games account for $41 \%$ of the memory span variance.

\footnotetext{
* Corresponding author at: Laboratory HAVAE, EA 6310, Faculty of Science, 123 Avenue Albert Thomas, 87060 Limoges, France. E-mail address: stephane.mandigout@unilim.fr (S. Mandigout).
} 
Conclusion: We have shown that encouraging physical activity can be based on the knowledge of many parameters, such as weight, age, gender and other bio-psycho-social parameters that must also be included in the model.

\section{Introduction}

The loss of autonomy due to age, disabilities, chronic pathologies or as a consequence of a sudden illness is both a personal affliction and a dire socio-economic issue [1]. Preservation of autonomy and recovery requires physical activity in order to tap into physiological resources and neurological plasticity [2]. However, as simple as this goal seems, more than $80 \%$ of patients do not comply with daily activity recommendations [3]. On the contrary, such patients significantly increase their sedentary lifestyle, which notably increases the risk of recurrence. Thus, it is essential to find strategies aimed at actively controlling, monitoring, and inciting such patients to improve their physical activity practices in a personalized way [4]. A thorough ecological monitoring of everyday activities at home could be an optimal solution [5]; any handicap is a complex combination of both previous health issues and contextual problems such as social and economic factors, as the International Classification of Functioning, Disability, and Health [6] shows. A first step is to ensure adequate data collection and analysis. Several "off the shelf" sensors exist. However, their reliability and ease of accessibility for raw data can be questioned $[7,8]$. Platforms are also used to better support patients. However, the results of the interventions are heterogeneous [9]. One reason may be that the devices do not use the optimal factors. Another reason would be that these devices do not adapt to the change in patient behaviour over time [2]. Finally, Godino et al. [10], in a study to assess the difference between subjective and objective measurement of physical activity in relation to sociodemographic, biological, behavioural, and psychological factors, showed that personalised feedback concerning physical activity may be an important first step to behaviour change. The aim of the present article is to present an experiment conducted during the AMISIA project. AMISIA a multidisciplinary, 36-month Defi CNRS AUTON project aimed at the secondary prevention of loss of autonomy for patients with traumatic brain injury and stroke. As "each patient is a unique case", AMISIA proposes an integrated approach, combining medical health devices, information technology, and human factors to provide patients, health care actors and family caregivers with both the best incentives and a high degree of monitoring. According to the medical research council, three scientific aims are targeted and defined in phase 1 "Modelling" [11]:

1- to study the ability to effectively monitor one's health by extracting relevant indicators effectively, to factor the information flux and to organize the information flowchart for longterm benefits,

2- to set up an adaptive system on which individualized incentive scenarios can be defined and combine them with assistance protocols using humans or robots,

3- to provide a leveraged effective feedback based on the information gathered through real in-context rehabilitation sessions performed on such scenarios.

These aims will be achieved in chronological order. In the present study, we conducted an ad hoc data collection in healthy adults likely to build a forward control database, intending to extract individual profiles to respond to the first aim.

\section{Material and methods}

\subsection{Study population}

The study design was transversal, prospective and single-centre. Before studying patients, we initially carried out this work in healthy adults, in order to correctly define the analytical methodology for future work with patients. Sixty-one students at Limoges University volunteered to participate in this study. The inclusion criteria for this study were: "healthy" and "adult". Exclusion criteria for this study were: "subject with visual or perceptual disorders"; "cognitive disorders"; "known neurological or psychiatric disorders"; "participants receiving treatment likely to influence memory"; "walking disease" and "subject over 35 years of age". All experimental protocols were carried out within the framework of supervised work in the fields of Kinesitherapy, Occupational Therapy and Speech Therapy training. Informed consent was signed by each participant before the study began.

\subsection{Experimental design}

The objective of our study was to define criteria allowing us to precisely determine individual strategies to encourage physical activity. For this, each participant underwent a battery of evaluations, which included:

- Physical activity level:

- A recording of physical activity level over seven days (Armband SenseWear, Bodymedia). The variables selected for this study were active energy expenditure (AEE), step count (SC) and activity at low, moderate and vigorous intensity,

- The evaluation of activity level using the International Physical Activity Questionnaire (IPAQ) [12].

- Socio-economic profiles: A socio-economic assessment to collect the parents' personal and professional situation, housing, daily life, habits (video games, Internet, social networks, sports activity), their satisfaction and resources.

- Psychological battery:

- Epworth Sleepiness Questionnaire [13],

- Profile of Mood States (POMS) [14],

- Fatigue severity scale (FSS) [15],

- Physical Activity for Health Purposes Motivation Scale (EMAPS) [16],

- Treatment-State Anxiety Inventory [17].

- Posture and gait measurement:

- An assessment of balance. This evaluation was carried out on a Wii-board platform using two methods (open and closed eyes), and information such as the stability index was collected on a tablet [18],

- Walking quality was evaluated based on a $10 \mathrm{~m}$ round-trip test (walking speed, cycle variability, double press time). A data recording from 4 inertial units was done (Xsense ${ }^{\circledR}$ ) [19].

- Cognitive performance:

- A mental imagery test consisting of performing the above walking test only in mental representation, without moving and with the eyes closed. When the participant starts the imaginary task, he gives the "top" start verbally, and when 

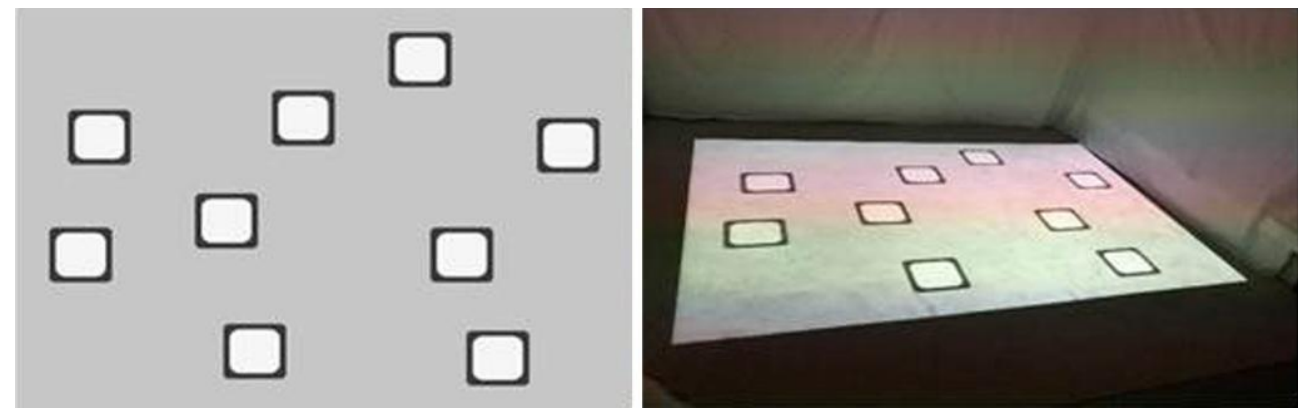

Fig. 1. Small and large scale Corsi test.

he thinks he's finished, gives the "top" stop. In parallel, his walking time was timed.

- Finally, each participant underwent a cognitive evaluation based on the Corsi test, in two different modalities: In near space (eCBT) and far space, with space navigation in an environment without spatial landmarks (Virtual Walk-Corsi test: VWCT, see Fig. 1) This work is presented in a recently published article [20].

\subsection{Statistics}

All participants were included in the analysis. Quantitative variables were described according to mean and standard deviation or median, interquartile range (IQR). The normality of the variables analysed was tested using the Shapiro-Wilk test. Comparisons between the two groups at each measurement time were made using a statistical test, such as the Student or Mann-Whitney test. Univariable linear regressions were performed to examine the relationships between physical activity level and span scores in eCBT and VWCT, in order to determine which of these should be integrated in the subsequent regression models. Separate multivariable linear regressions were run to examine whether physical activity variables would predict span scores in different spaces. The statistical analysis was performed using IBM SPSS ${ }^{\circledR}$ Statistics version 23 (IBM Corp, Armonk, USA), and result significance was set at $\mathrm{p}<$ 0.05 .

\section{Results}

Sixty-one participants (20 men and 41 women, mean age: $23 \pm$ 3 years) were included in our study. Table 1 shows the characteristics of the participants included in the study. Two groups were formed based on the scores in the VWCT: Group A ( $\mathrm{n}=30)$, memory span less than 7 and Group B $(n=31)$, memory span more than 7 , the span 7 being the median of our population sample.

For the VWCT, the median memory span for Group A was significantly less $(p<0.001)$ than for Group B. Step count AEE, AEEmod and AEEvig were significantly higher in Group B $(\mathrm{p}<0.05)$. Significant correlations were obtained between the score in the VWCT and the AEE $(\mathrm{r}=0.51, \mathrm{p}<0.001)$ and the AEE, greater than 3 METs ( $r=0.486, p<0.001$ ) (Fig. 2). However, we found no difference between groups for the IPAQ score. Additionally, the sociodemographic questionnaire revealed that participants from Group B were more prone to play video games than participants from Group A. Fatigue questionnaire results also showed that participants from Group A had a higher fatigue level than participants from Group B ( $\mathrm{p}=0.05)$. There was no significant difference between Group A and B for the other variables (Gait quality, posture, anxiety, motivation, sleep). A multiple regression analysis showed that gender, AEE, fatigue and tendency to play video games accounted for $41 \%$ of the memory span variance.

\section{Discussion}

Cognitive disorders are strongly present in traumatic brain injury or stroke patients. This constitutes a limitation in activity and the return to a healthy social life. This study, even though we included only healthy young subjects, allows us to postulate that the cognitive disorders could be partly explained by the lack of activity, and also by a state of more significant fatigue. Our study reports a few other criteria that may explain the variance of the span. The lack of effect for these criteria can be explained by the characteristics of our subjects, who were young and healthy. However, improved identification of (i) the primary symptoms of activity restriction and limitation of participation, and (ii) the criteria explaining the majority of these variations, should help to define the individual motivational strategy for the activity. If all of this analysis can be done via a sensor and an application (adapted dashboard), then it will be easier to monitor the patient and provide advice for a successful home return. Additionally, these data will help build a control database, extracting individual profiles with machine learning techniques. Ultimately, the AMISIA project will focus on three directions:

The first direction is pursuing the work on data collection, treatment, and interpretation: A set of sensors and traditional approaches will be combined to produce interpretable data for follow-up and future evaluations [20]. This objective will address data presentation in personalized scoreboards for the patient, the medical team and the caregivers. Heterogeneous in nature and massive in volume, the data will need a flexible storage solution [21]. The ability to insert additional data collection devices "on the fly" or other services will be addressed here.

The second direction is the design and the classification of sets of personalized scenario building blocks: Based on upstream defined indicators and personæ modelling, we shall first develop an adaptive system able to generate personalized scenarios as the concatenation of elementary items, also known as 'grains' [22]. Thanks to an intuitive interface, the medical team will be able to provide several scenarios, organized in classes. Scenario relevance, ease of use and scope of classes will be evaluated.

The third direction is the implementation of incentive scenarios: This involves studying how to help the participants recover or discover a beneficial physical activity in a personalized manner. It will combine human and robotic system-assisting interventions $[23,24]$. The acceptability and usability of such interactions and intervention proposals will be evaluated, especially at the social level. The use of artificial intelligence can be an excellent way to monitor and encourage each person's profile. Recent studies, such as those by Stein et al. [25], have shown a decrease in weight in obese patients with a robotic system using artificial intelligence, including elements of behavioural therapy. 
Table 1

Baseline demographic and functional characteristics.

\begin{tabular}{|c|c|c|c|}
\hline & $\begin{array}{l}\text { Total sample } \\
(\mathrm{n}=61)\end{array}$ & $\begin{array}{l}\text { Group A } \\
(n=30)\end{array}$ & $\begin{array}{l}\text { Group B } \\
(n=31)\end{array}$ \\
\hline \multicolumn{4}{|l|}{ Characteristics } \\
\hline Age (Year) & $22(3)$ & $123.0(3)$ & $22.0(3.5)$ \\
\hline Gender $(M / F)$ & $20 / 41$ & $15 / 20$ & $15 / 21$ \\
\hline Height $(\mathrm{m})$ & $1.69(0.18)$ & $11.63(0.14)$ & $1.71(0.18)$ \\
\hline Weight (kg) & $66.3(16.2)$ & $163.6(13.8)$ & $72.6(16.7)$ \\
\hline \multicolumn{4}{|l|}{ Cognitive performance } \\
\hline$\overline{\mathrm{eCBT}}$ & $7(1)$ & $17(1)$ & $8(2)^{* *}$ \\
\hline VWCT & $6(1.5)$ & $16(1)$ & $7.5(1.0)^{* * *}$ \\
\hline Gait time (s) & $20.0(3.5)$ & $120.0(4.0)$ & $20(2.7)$ \\
\hline Mental imagery test (s) & $16(6)$ & $117.0(7.5)$ & $15.5(5.5)$ \\
\hline \multicolumn{4}{|l|}{ Physical activity level } \\
\hline Step count & 7573 (4902) & $17538(3255)$ & $8487(6470)^{* *}$ \\
\hline AEE (kcal) & $2448(750)$ & $12214(353)$ & $2853(889)^{* *}$ \\
\hline AEE $\bmod (\mathrm{kcal})$ & 159 (119) & $1119(96)$ & $169(93)^{* *}$ \\
\hline AEE vig (kcal) & $8(13)$ & $16(10)$ & $9(15)^{*}$ \\
\hline IPAQ (MET.day) & 1277 (2703) & $11413(1772)$ & $1193(3406)$ \\
\hline \multicolumn{4}{|l|}{ Psychological battery } \\
\hline Epworth sleepiness & $9(5)$ & $110(4.5)$ & $8(6)$ \\
\hline FSS & $3(2)$ & $13(2)$ & $3(1)^{*}$ \\
\hline State anxiety & $38(16)$ & $139(25)$ & $38(12)$ \\
\hline Treatment anxiety & $50(4)$ & $149(5)$ & $51(5)$ \\
\hline POMS & $21.0(28.5)$ & $121.0(26.5)$ & $21(35.5)$ \\
\hline Intrinsic motivation & $7.7(1.7)$ & $15.7(1.0)$ & $5.8(2.3)$ \\
\hline Extrinsic motivation & $5.3(2.7)$ & $15.0(2.7)$ & $5.7(2.7)$ \\
\hline Amotivation & $1.0(1)$ & $11.0(0.01)$ & $1.0(3.0)$ \\
\hline \multicolumn{4}{|c|}{ Posture and gait measurements } \\
\hline Gait speed (m.s $\left.{ }^{-1}\right)$ & 1.10 .2 & $1.1(0.2)$ & $1.1(0.2)$ \\
\hline Gait step (ms) & $0.500(0.001)$ & $0.500(0.001)$ & $0.500(0.001)$ \\
\hline Double press time (\%) & $23(4)$ & $23(4)$ & $23.0(4.5)$ \\
\hline Bal speed EO $\left(\mathrm{mm} \cdot \mathrm{s}^{-1}\right)$ & $0.7(0.2)$ & $0.7(0.2)$ & $0.7(0.2)$ \\
\hline Bal speed EC $\left(\mathrm{mm} \cdot \mathrm{s}^{-1}\right)$ & $1.1(0.5)$ & $1.1(0.5)$ & $1.1(0.3)$ \\
\hline Bal area $\operatorname{EO}\left(\mathrm{mm}^{2}\right)$ & $1.8(0.9)$ & $1.8(0.8)$ & $1.8(0.9)$ \\
\hline Bal area EC $\left(\mathrm{mm}^{2}\right)$ & $2.4(1.6)$ & $2.7(1.4)$ & $2.3(1.9)$ \\
\hline Stability EO (\%) & $99(1)$ & $99(1)$ & $99(1)$ \\
\hline Stability EC (\%) & $99(2)$ & $99(2)$ & $99(2)$ \\
\hline
\end{tabular}

Median (IGR: Interquartile range); eCBT: Corsi test in near space; VWCT: Virtual walk-Corsi test; AEE: Active energy expenditure; POMS: Profile of Mood States, FSS: The fatigue severity scale (FSS); Bal: Balance. Significant difference between $A$ and $\mathrm{B} * \mathrm{p}<0.05, * * \mathrm{p}<0.01, * * * \mathrm{p}<0.001$.

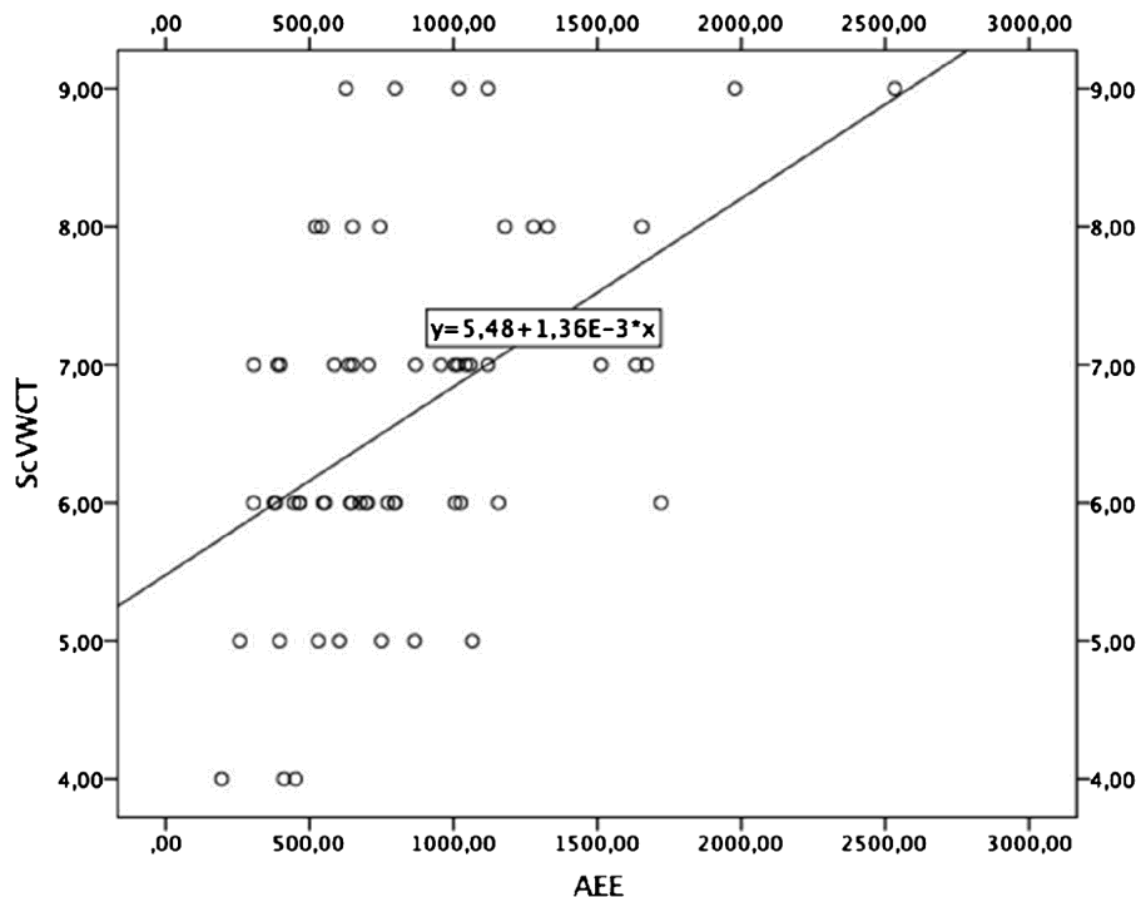

Fig. 2. Relationship between active energy expenditure (AEE) and the score on the walking Corsi test (SC VWCT). 


\section{Conclusion}

We have shown in our study that encouraging physical activity cannot be based on knowledge of only a few parameters, such as weight, age, and gender. Other bio-psycho-social parameters must also be included in the model. Further studies, integrating artificial intelligence, will be needed to improve strategies to promote physical activity among patients with loss of autonomy.

\section{Human and animal rights}

The authors declare that the work described has been carried out in accordance with the Declaration of Helsinki of the World Medical Association revised in 2013 for experiments involving humans as well as in accordance with the EU Directive 2010/63/EU for animal experiments.

\section{Informed consent and patient details}

The authors declare that this report does not contain any personal information that could lead to the identification of the patient(s).

The authors declare that they obtained a written informed consent from the patients and/or volunteers included in the article. The authors also confirm that the personal details of the patients and/or volunteers have been removed.

\section{Funding}

This work has been supported by CNRS through the MITI interdisciplinary programs.

\section{Author contributions}

All authors attest that they meet the current International Committee of Medical Journal Editors (ICMJE) criteria for Authorship.

\section{CRediT authorship contribution statement}

S. Mandigout: Conceptualization, Writing - original draft. A. Perrochon: Conceptualization, Funding acquisition. L. Fernandez Supervision. N. Rezzoug: Validation. B. Encelle: Supervision. I. Kanellos: Supervision. D. Ricard: Writing - review \& editing. M. Bouet: Writing - review \& editing. M. Shneider: Writing - review \& editing. S. Buffat: Writing - original draft.

\section{Declaration of competing interest}

The authors declare that they have no known competing financial or personal relationships that could be viewed as influencing the work reported in this paper.

\section{Acknowledgements}

We are thankful to the MITI interdisciplinary programs (CNRS) for their scientific insights and unyielding support.

\section{References}

[1] Robin S, Giraud J, Moreau F. Autonomie des personnes âgées. Synthèse documentaire dans le cadre de la mise en place des plateformes de santé publique à l'ARS de Poitou-Charentes. ORS Poitou-Charentes; févr. 2014. 79 pages.

[2] Billinger SA, et al. Physical activity and exercise recommendations for stroke survivors: a statement for healthcare professionals from the American Heart
Association/American Stroke Association. Stroke 2014;45(8):2532-53. https:// doi.org/10.1161/STR.0000000000000022.

[3] Marcus BH, et al. Physical activity behavior change: issues in adoption and maintenance. Health Psychol 2000;19(1S):32.

[4] Marshall SJ, Biddle SJ. The transtheoretical model of behavior change: a meta analysis of applications to physical activity and exercise. Ann Behav Med 2001;23(4):229-46.

[5] Michie S, Johnston M. Theories and techniques of behaviour change: develop ing a cumulative science of behaviour change. Taylor \& Francis; 2012

[6] WHO | International classification of functioning, disability and health (ICF) WHO [en ligne]. Disponible sur: http://www.who.int/classifications/icf/en/. [Consulté le: 13-févr-2020].

[7] Mandigout S, Lacroix J, Ferry B, Vuillerme N, Compagnat M, Daviet J-C. Can energy expenditure be accurately assessed using accelerometry-based wearable motion detectors for physical activity monitoring in post-stroke patients in the subacute phase? Eur J Prev Cardiol 2017;24(18):2009-16. https://doi. org $/ 10.1177 / 2047487317738593$.

[8] Mandigout S, Vuillerme N, Borel B, Perrochon A, Lacroix J, Mandigout S. Measuring the daily energy expenditure related to physical activity by actigraphy: comparative study. Ann Phys Rehabil Med 2016;59:e52. https://doi.org/ 10.1016/j.rehab.2016.07.119.

[9] Maddison R, et al. mHealth interventions for exercise and risk factor modification in cardiovascular disease. Exerc Sport Sci Rev 2019;47(2):86-90. https:// doi.org/10.1249/JES.0000000000000185.

[10] Godino JG, Watkinson C, Corder K, Sutton S, Griffin SJ, van Sluijs EMF. Awareness of physical activity in healthy middle-aged adults: a cross-sectional study of associations with sociodemographic, biological, behavioural, and psychological factors. BMC Public Health 2014;14:421. https://doi.org/10.1186/1471-245814-421.

11] Craig P, Dieppe $P$, Macintyre S, Michie S, Nazareth I, Petticrew M. Developin and evaluating complex interventions: the new Medical Research Council guidance. BMJ 2008:a1655. https://doi.org/10.1136/bmj.a1655.

[12] Cleland CL, Hunter RF, Kee F, Cupples ME, Sallis JF, Tully MA. Validity of the Global Physical Activity Questionnaire (GPAQ) in assessing levels and change in moderate-vigorous physical activity and sedentary behaviour. BMC Public Health 2014;14(1):1255. https://doi.org/10.1186/1471-2458-14-1255.

[13] Doneh B. Epworth sleepiness scale. Occup Med (Lond) 2015;65(6):508. https:// doi.org/10.1093/occmed/kqv042.

[14] Fillion L, Gagnon P. French adaptation of the shortened version of the Profile of Mood States. Psychol Rep 1999;84(1):188-90. https://doi.org/10.2466/pr0.1999. 84.1.188.

[15] Krupp LB, LaRocca NG, Muir-Nash J, Steinberg AD. The fatigue severity scale. Application to patients with multiple sclerosis and systemic lupus erythematosus. Arch Neurol 1989;46(10):1121-3. https://doi.org/10.1001/archneur.1989. 00520460115022.

[16] Boiché J, Gourlan M, Trouilloud D, Sarrazin P. Development and validation of the "Echelle de Motivation envers l'Activité Physique en contexte de Santé": a motivation scale towards health-oriented physical activity in French. J Health Psychol 2019;24(3):386-96. https://doi.org/10.1177/1359105316676626.

[17] Vigneau F, Cormier S. The factor structure of the state-trait anxiety inventory: an alternative view. J Pers Assess 2008;90(3):280-5. https://doi.org/10.1080/ 00223890701885027.

[18] Bargiotas I, et al. On the importance of local dynamics in statokinesigram: a multivariate approach for postural control evaluation in elderly. PLoS ONE 2018;13(2):e0192868. https://doi.org/10.1371/journal.pone.0192868.

[19] Barrois R, et al. An automated recording method in clinical consultation to rate the limp in lower limb osteoarthritis. PLoS ONE 2016;11(10):e0164975. https:// doi.org/10.1371/journal.pone.0164975.

20] Perrochon A, et al. The influence of age in women in visuo-spatial memory in reaching and navigation tasks with and without landmarks. Neurosci Lett 2018;684:13-7. https://doi.org/10.1016/j.neulet.2018.06.054.

[21] Shull PB, Jirattigalachote W, Hunt MA, Cutkosky MR, Delp SL. Quantified sel and human movement: a review on the clinical impact of wearable sensing and feedback for gait analysis and intervention. Gait Posture 2014;40(1):11-9. https://doi.org/10.1016/j.gaitpost.2014.03.189.

[22] Abu-Elkheir M, Hayajneh M, Ali NA. Data management for the internet of things: design primitives and solution. Sensors (Basel) 2013;13(11):15582-612. https://doi.org/10.3390/s131115582.

[23] Koenitz H, Ferri G, Haahr M, Sezen D, Sezen TI, editors. Interactive digital narrative: history, theory and practice. New York: Routledge; 2015.

[24] Carr LJ, et al. Randomized controlled trial testing an internet physical activity intervention for sedentary adults. Health Psychol 2013;32(3):328-36. https:// doi.org/10.1037/a0028962.

[25] Stein N, Brooks K. A fully automated conversational artificial intelligence for weight loss: longitudinal observational study among overweight and obese adults. JMIR Diabetes 2017;2(2):e28. https://doi.org/10.2196/diabetes.8590. 